\title{
Working with IoT - A Case Study Detailing Workplace Digitalization Through IoT System Adoption
}

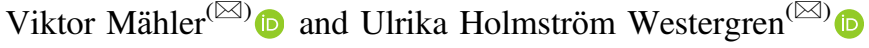 \\ Department of Informatics, Umeå University, 90187 Umeå, Sweden \\ \{viktor.mahler, ulrika.westergren\}@umu. se
}

\begin{abstract}
As the Internet of Things (IoT) continues to grow in scope it is bound to pervade an increasing number of firms. To that end it becomes important to understand the challenges and opportunities associated with introducing IoT in the workplace. By studying IoT implementation and usage from the perspective of three different stakeholders cooperating around the same IoT system, we explore how the introduction of IoT in the workplace presents unique opportunities and challenges for both management and individual workers. We conclude that the identified opportunities expressed by the different stakeholders were increased productivity, the ability to monitor performance, and improved customer relations. Challenges encountered were increased stress among some workers and forming a shared understanding of the IoT system's capabilities amongst different stakeholders.
\end{abstract}

Keywords: Internet of Things $\cdot$ Digitalization $\cdot$ Building maintenance

\section{Introduction}

The digital transformation of the workplace is an ongoing process for firms that are striving to stay relevant within today's business environment. Moving towards a digital profile is to some extent inevitable, as information technology (IT) pervades all types of branches and sectors. Thus, the real question lies within how this transformation is imagined and implemented both from a management perspective as well as by individual workers. Previous research has highlighted the need for a processual and contextual understanding of the role of IT within the workplace [18] in order to capture, for example, the situated use of IT [17, 28], IT value [13, 15], IT usage and communities of practice [7], and effects on demands for skilled labor [2]. However, as IT is constantly evolving, there is need for more research that takes into account the new solutions and offerings that are currently on the market, impacting workplaces in new ways.

This paper targets the Internet of Things (IoT) as an emerging technological paradigm. Current estimates say that in 2020 there will be 20 billion connected products globally, and numbers are expected to rise. Naturally a large number of these products and solutions will be implemented within workplace environments, where the 
capture, transmission and analysis of contextual data will be used to increase efficiency, transparency and effectiveness [8]. As we are only in the first stages of the IoT, most of the research so far has focused on technological, architectural and infrastructural requirements in order to set up a functioning IoT-network [31]. Although there is an emerging stream of research that focuses on organizational impacts of IoT, for example IoT business models and on IoT ecosystems [20, 21, 25, 26], there are few empirical studies about how the introduction of IoT in the workplace will affect organizational strategy, worker conditions, and possibilities for value creation [33].

In this study we follow the digitalization of building maintenance in the form of an IoT system designed for efficient cleaning services and ask the question: What are the challenges and opportunities associated with introducing IoT in the workplace? By studying IoT implementation and usage from the perspective of three different stakeholders: the building/operations management of the firm, the IoT system provider, and the cleaning services provider, we aim to show how the introduction of IoT in the workplace has implications on professional life. By conducting interviews with key personnel, reviewing existing research and analyzing our case through the Technological Frames framework [19], we capture people's understanding of the IoT, thereby contributing to the discourse on IT in organizations in general and IoT in the workplace in particular. We conclude that the identified opportunities expressed by the different stakeholders were increased productivity, the ability to monitor performance, and improved customer relations. Challenges encountered were increased stress among some workers and forming a shared understanding of the IoT system's capabilities amongst different stakeholders.

The paper proceeds as follows: In the next section we give an overview of related research regarding the digital workplace and the IoT. In Sect. 3 we introduce our theoretical framework, followed by methodology and results in Sects. 4 and 5. We end the paper with a discussion of the results and conclusions and provide suggestions for further research.

\section{Related Research}

\subsection{The Digital Workplace}

Ever since technology was first introduced in the workplace in the 1950s, scholars have attempted to understand and explain the social and organizational consequences of information technology $[11,23,24,30]$. Earlier research shows, for example, how IT has been linked to worker productivity, by reducing the cost of information exchange and providing access to knowledge needed for project multitasking [1]. In addition, it has been shown that employees' adoption of IT is strongly influenced by co-workers' attitudes, pinning social factors as one of the most important adoption factors, along with training and management support [7], and the involvement of affected parties within an organization to facilitate a successful implementation of IT [4]. Furthermore, it has made possible the extensive electronic monitoring of employees, adding layers of 
legal, ethical and privacy aspects to the mix [16]. As IT has evolved and continues to pervade professional life, the concept of the digital workplace has emerged in information systems research, denoting a context where workers are exposed to a multitude of digital tools that allow for both collaboration and mobility, but also require a certain compliance and may lead to undesirable outcomes in terms of stress and overload [12].

In order to become a digital workplace, the organization must actively engage in a process of digitalization. As devices and networks start to be able to communicate and process information amongst one another they achieve convergence, which - when reaching a certain point - will allow for the social infrastructures to converge and change to fit the technology. This may change the way the business itself operates, combining several different aspects to achieve a new way of working, and providing a pervasive system that garners support and increases likelihood of being used [29, 34]. A current example of the entanglement of digital technology and organizational infrastructure is seen in the organizational adoption of IoT, which imposes new opportunities and challenges for the digital workplace.

\subsection{The Internet of Things}

The IoT denotes a technological paradigm where physical and digital systems melt together to form cyber-physical systems [3]. The common theme is a non-separable combination of physical hardware and digital software along with sensors, data storage and remote connectivity. The ongoing and rapid expansion of an affordable ITinfrastructure together with new technological developments driving miniaturization of components, has driven the costs of hardware ever downward [5], virtually removing the threshold for adding connectivity to everyday consumer products. In addition, there has been an ongoing strive for platforms and application programming interfaces to permit interoperability, which is crucial if IoT systems are going to be able to scale [27].

The IoT has so far mostly been studied from a technological, architectural and infrastructural perspective and less is known about the organizational implications of IoT $[31,33]$. However, as the IoT is expected to grow in scope, many firms are seeing opportunities for value creation through the capture and analysis of data. For some firms this means moving from selling products to selling services, for others the IoT can provide new markets where already existing services are enhanced by the provision of contextual data. For yet others, the IoT offers new opportunities to apply existing skill sets, for example in data analysis or interface design [26]. In addition, the IoT is expected to be developed by ecosystems of firms, where one firm might deliver the technology, another the implementation context, and a third provide the services based on the captured data $[20,25]$. Such a collaborative environment presumes overlapping ambitions and mutual goals, but different stakeholders might have divergent perspectives on both value creation and organizational implications of IoT implementation.

Furthermore, the IoT offers unprecedented access to data about products, processes and people. Data that is generated and captured can be analyzed to distinguish employee work patterns as well as customer behaviors and organizations. Firms therefore need to 
make strategic choices about data management [20] as well as strive to create a balance between trust, security and privacy concerns [6]. In sum, in order to explore the implications of introducing the IoT in the workplace, one must consider not only the IoT system and its service offerings, but also the perspectives of the ecosystem stakeholders and their respective notions of IoT value production and capture.

\section{Theoretical Framework}

In order to capture and understand the perspectives of different IoT ecosystem stakeholders we use the Technological Frames framework developed by Orlikowski and Gash [19]. The concept or technological frames is that there exists underlying assumptions, interpretations, and expectations of a system; technological frames - and these frames might widely differ between different groups in an organization; such as those in a managerial position, workers and technicians. Technological frames may have a powerful effect on the adoption of new technology as they will strongly influence the choices that are made; in regards to the design and the use of the technologies when presented to workers [19].

If the expectations and the assumptions made by the various groups are running along similar lines then congruence is achieved - meaning that the view of the system is shared in its intended functionality. If the viewpoints, on the other hand, are incongruent, it means that the frames do not match between the groups - for example a manager expecting a system to deliver something entirely different than what the workers are expecting. The end result of frame incongruence had been observed as the eventual cancelation of the project in which it was identified, and that it can have severe negative impacts where it is prevalent $[9,19]$.

The Technological Frames framework contains three main concepts; Nature of technology, representing the understanding of the functionality and potential of technology. Technology Strategy, meaning the view of what technology might add to the organization and the reason for its implementation. And Technology-in-use; being the everyday use of the technology and the consequences deriving from its usage [19]. By using this framework, we are able to highlight different views and perspectives and detect both congruent and incongruent frames in regards to IoT adoption.

\section{Research Methodology}

We chose to perform a qualitative case study $[10,32]$ in order to gain an insight into the personal thoughts and reasons presented by key personnel amongst the three stakeholders, being the cleaning service provider, the building manager and the system provider. The main method of data collection was through semi-structured interviews [14], where the rationale behind the IoT system implementation, viewpoints, challenges and positive effects were discussed at length in order to create an understanding for both the technology and the technological frames present within the three stakeholder groups. 
By examining key actors' taken-for-granted notions of technology, we were able to draw insights into the development, usage and implications of introducing IoT within the workplace.

\subsection{Research Context}

The three actors related to this are - BuildingCo, a sporting facility owning a large building complex featuring recreational activities, with roughly 4000 visitors every week, CleanCo, a large organization offering cleaning services; where this is one of their contracts (with an assigned cleaning crew), and a SystemCo; delivering both the IoT system and cleaning products (with the IoT system being our primary focus).

BuildingCo had moved towards implementing a new system when the old cleaning company that had been working for them was fired due to complaints and inadequate performance output. BuildingCo, together with the new cleaning provider, CleanCo, aimed to provide a better service and through that reduce complaints. Along came SystemCo, offering BuildingCo a chance to install their brand new IoT system.

The IoT system was a complete service purchased from SystemCo; which already sold the cleaning products used by BuildingCo; such as paper towels, toilet paper, soap and various other supplies. In installing this IoT system, the soap- and paper dispensers were outfitted with sensors measuring the volume dispensed by the containers, as well as visitor counters, counting the number of people that frequented critical areas; such as toilets and shower facilities.

Data that is gathered through the various sensors is wirelessly transmitted to wallmounted receivers placed throughout the building. These receivers have a vastly larger bandwidth and processing power than individual sensors. The receivers then transmit the aforementioned data to a cloud based service where statistics are measured and organized in a graphical user interface accessible to the building/operations manager for BuildingCo, team-leaders of CleanCo, and SystemCo themselves.

BuildingCo has been using this system for roughly one and a half years, allowing for it to become a daily aspect of their organization, relying upon it for the cleaning being performed, but also serving as a pilot organization for SystemCo.

\subsection{Data Collection}

The data was collected using snowball sampling where the building manager was first approached. Said manager then referred us to other key actors responsible for the IoT system itself and actors both on the service-side and the operational-side of the organization. The snowball sampling is recommended when dealing with small populations featuring specific characteristics; which in this case was high-level access to the IoT system [22]. From this sampling a total of 14 interviews were performed, featuring personnel from CleanCo, the building manager responsible for the purchase and system as well as personnel from SystemCo. The average interview lasted $50 \mathrm{~min}$ with a maximum of $170 \mathrm{~min}$. All interviews were audio-recorded and transcribed (Table 1). 
Table 1. A table detailing the interview respondents, their roles and the number of interviews performed with each of the respondents.

\begin{tabular}{l|l|l|l}
\hline Actor role & Person & Role of respondent & No. of interviews \\
\hline \multirow{4}{*}{ CleanCo } & P01 & Team-leader, system manager & 2 \\
\cline { 2 - 4 } & P02 & Team-leader, system manager & 1 \\
\cline { 2 - 4 } & P03 & Team-leader & 1 \\
\cline { 2 - 4 } & P04 & Cleaner & 1 \\
\cline { 2 - 4 } & P05 & Cleaner & 1 \\
\cline { 2 - 4 } & P06 & Cleaner & 1 \\
\hline \multirow{5}{*}{ BuildingCo } & B01 & Building-/operations manager & 2 \\
\hline & S01 & Customer relations/product owner & 2 \\
\cline { 2 - 4 } & S02 & Sales representative & 2 \\
\cline { 2 - 4 } & S03 & Technical manager & 1 \\
\hline
\end{tabular}

\subsection{Data Analysis}

Data was analyzed through the Technological Frames framework [19] and the analysis was performed in two different stages. First, we read through all interviews pertaining to a specific stakeholder firm and coded the data into the three theoretical categories of nature of technology, technology strategy, and technology in use. We have included some sample sentences and their applied codes (see Table 2) to illustrate our coding process. In the second stage, we performed a cross-case analysis searching for both common themes and opposing viewpoints between the different stakeholders. At this point we also looked for congruent and incongruent frames within and between firm groups. The results are presented in the next section. All firm names have been anonymized to protect privacy.

Table 2. Examples of sample sentences and their respective coding.

\begin{tabular}{|c|c|c|}
\hline Sample sentence & Respondent & Coded as \\
\hline $\begin{array}{l}\text { "[...] Now we can see that if it is supposed to give } \\
\text { [value] to a customer we have to deliver the big } \\
\text { picture, you can't just provide them with a small part } \\
\text { - because then we would only have a tiny target } \\
\text { audience, and then we would be finished." }\end{array}$ & S01 & $\begin{array}{l}\text { Nature of technology } \\
\text { "What IoT is and does" }\end{array}$ \\
\hline $\begin{array}{l}\text { "I would... If I were to guess, I'd say that everything } \\
\text { boils down to statistics, but in the end it all becomes } \\
\text { an economic issue, being able to see how many } \\
\text { visitors, being able to see how much paper and such } \\
\text { that is used, in order to make it more effective, and to } \\
\text { maximize the income." }\end{array}$ & P02 & $\begin{array}{l}\text { Technology Strategy } \\
\text { "What IoT adds" }\end{array}$ \\
\hline $\begin{array}{l}\text { "You can see whether it [the statistics] changes; goes } \\
\text { up or goes down, and then you can compare them } \\
\text { and see 'Well now the critical time has increased, and } \\
\text { why has it done that?'. If I see that the critical time is } \\
7 \text { - that won't tell me anything, but if it used to be } 7 \\
\text { and goes to } 14 \text {, then it tells me something." }\end{array}$ & B01 & $\begin{array}{l}\text { Technology-in-use "How } \\
\text { IoT will be used" }\end{array}$ \\
\hline
\end{tabular}




\section{Results}

The results section is structured according to the three theoretical concepts and the three stakeholders, discussing the Nature of technology, Technology strategy and Technology-in-use from the point of view of the different actors. The main findings are then summarized in Table 3. However, we start out with a description of the IoT system and its actual implementation and use.

\subsection{An IoT System for Efficient Cleaning Services}

System as Used by CleanCo Cleaners. The IoT sensors were connected to an application, that the cleaners accessed via a tablet attached to their respective cleaning carts. A green marker indicated a recently filled dispenser or cleaned area; a yellow marker (only used by the dispensers) indicated a need for refill (e.g. a soap-, toilet paper- or paper towel-dispenser having less than half of its contents left); and a red marker that the dispenser was empty or that an area has reached its maximum amount of visits (with an upper limit of 20 selected by the building/operations manager). The area or dispenser corresponding with the sensor moves up on the cleaners" "to-do"-list depending on the status, with red sensors at the top of the list, then yellow and lastly green. The cleaners were expected to address the red and/or yellow markers as they showed up, thus being flexible enough in their work to, when needed, deviate from a pre-set cleaning plan that they would otherwise adhere to.

System as Used by CleanCo Team-Leaders. The team-leaders of the cleaning crew had some added accessibility, for example the ability to add new cleaning-plans detailing how the cleaners should work when not responding to sensors, and to edit existing ones. The system also featured the ability for team-leaders to send out messages to the cleaners, showing up on their tablets and potentially alerting them to certain situations such as broken windows or leaking pipes that would otherwise not be covered by the sensors placed throughout the facility. Team-leaders could also access statistics regarding specific sensors, for example; how long a certain sensor had been red during a particular time-span; or how many visitors there had been in particular zones during certain times. This allowed them to adjust cleaning plans or perform quality assurance on the various areas within the building itself.

System as Used by BuildingCo. The building manager used the statistics provided through the system to monitor overall productiveness, see trends, and identify potential bottlenecks with a significantly higher visitor count or higher usage of supplies. The system and its produced statistics could also serve as a measurement for procurements when it comes to supplies or even as a baseline for labor, should the management choose to hire another company to handle the cleaning service. In this sense the system allowed for both quality assurance, increased negotiating power and also a way to more effectively and accurately monitor the cleaners in their work, and with what speed and detail that various tasks were completed.

System as Used by SystemCo. While SystemCo was less interested in the day-to-day operations, the IoT system and the statistics that it provided, gave an increased 
understanding of the customer's business and made it possible to tailor sales and other services based on the customer data, for example being able to predict when certain supplies were running out and (hypothetically) pricing the supplies according to the demand for them by the customer. The implementation also facilitated a relationship between the SystemCo and BuildingCo, as continuous coordination benefits both parties - where the building/operations manager receives reports, support and updates that are being produced by SystemCo. Forming a close relationship with the customers can potentially dissuade them from switching to another system provider.

\subsection{Nature of Technology}

Nature of technology refers to stakeholders' understanding of the IoT system, its functionality, and its possibilities.

CleanCo. When asked about the system itself, it was generally well received by both cleaners and team-leaders (who themselves also did operational work to some extent). The task of cleaning could be split into "need-based" and "frequency-based" cleaning, where the "need-based" cleaning was relying solely on the sensor data, in that cleaning would be performed according to whether system prompts were red or yellow, and the "frequency-based" cleaning was simply following a pre-determined schedule. One of the respondents, who had previously worked frequency-based at a larger building complex, stated that a system such as this would eliminate the uncertainty of whether or not an area had been cleaned comparing it to their previous workplace;

"We did not know exactly at which times anybody had been in there [cleaning]. Then you might run over there when somebody had already been there."

This viewpoint was shared amongst the other respondents, detailing similar stories of previous uncertainty regarding their cleaning schedules. When asked if they were worried about the possibilities of having their work monitored, neither of the respondents reported that this was anything that they were personally worried about. Overall the cleaners themselves held the system in high regard both before and after the implementation process itself.

Building Co. The rationale for adopting the IoT system and digitalizing the cleaning process was mainly due to the fact that a lot of complaints had arisen from customers using the facilities when a previous company provided the cleaning services, with the building/operations manager stating that;

"We had a lack of quality, so now we have the same amount of cleaners but we have a significantly better result. That was not the case one and a half, or two, years ago. Back then we had a lot of [complaints]... and most of the complaints were regarding the cleaning".

As the previous cleaning service was replaced, SystemCo (that was only the supplier of cleaning products at that point) approached the building manager and sold their concept of a digitalized cleaning solution. In the wake of the complaints, that had arisen with the previous cleaning company; being able to monitor the cleaning process and getting an overarching view of the facilities proved to be one of the main motivators for the management team and allowing the procurement of the IoT system, adding an additional level of value, being able to have actual statistics of the work being performed. 
SystemCo. When asked about the system, much of the reasoning behind the development was that it would add simplicity for the cleaners themselves. This reasoning was expanded, stating that the addition of the system would give cleaners more freedom, streamlining their work and creating additional value through the aforementioned aspects. Another factor in regards to value creation was that cleaners would feel that someone invested in them by adding technology to enhance their work, something which, according to SystemCo, often gets overlooked or kept at a minimum in most cases in regards to maintenance workers. This would, it was argued, also lead to an increased sense of professional pride amongst the cleaners. One of the system providers argued that;

"Well the cleaners think it's a bit fun that their work is seen, [...] All of a sudden they get a tablet and you look at their work - it gives people another status".

The possibilities for SystemCo themselves were that when moving in on, or approaching, new customers, the strategic benefits of the IoT system could be argued, and that aspect seemed to be, although stated more implicitly, a larger and more important factor than the cleaners' wellbeing. The added benefits, argued to potential customers, would hence be the ability to have a better view of the cleaning process, and an increased quality assurance.

\subsection{Technology Strategy}

Technology strategy refers to stakeholders' views on what IoT might add to their organization and what the reason is for technology adoption.

CleanCo. The strategic value that the cleaners, and the team-leaders in particular, expressed regarding the system was primarily the ability to centralize the schedules that went out to the various cleaning crews. For instance, in regards to the cleaning of specific areas that required certain chemicals or cleaning agents, the mixtures and compositions could be delivered directly to the cleaners doing their rounds. On the operational level the strategic value was that the system would decrease the amount of check-ups required within different areas, primarily toilets, where the cleaners would not have to open up all the dispensers in order to check the status of toilet paper, paper towels or soap.

This decrease in workload was perceived to be valuable, and from a quality standpoint it would also allow for the cleaners to attend to more areas, creating a better environment in general. When it came to the ability to plan; team-leaders felt that scheduling within the application did not provide them with any benefits, or as one of team-leaders described the hypothetical scheduling for individuals;

"[...] If there are a lot of users it would require extensive administration from us, and since we're in-house that would make it very inflexible."

Because of this, the managing of schedules and planning of individual cleaners was still done outside of the system, using a whiteboard with corresponding times for each of the cleaners. 
BuildingCo. For the building/operations manager the primary strategic value was described as the ability to use the statistics provided by the system to monitor the cleaning procedure, gauge differences in time and/or quality, as well as to use the system to get a baseline for future procurements of products, and eventually if hiring a new cleaning company - to be used as a comparison, with the manager stating that;

"[It's] on the level that I evaluate if they do a good job, or... we want as little critical time as possible, so I can look at it when I'm going to discuss with their managers, and then we might have others looking at the details in the system".

In the wake of the complaints that were received with the previous company, much of the arguments for the strategic values revolved around the ability to, in a sense, "control" how the work was being performed, and to deal with it accordingly, and was discussed to roughly the same extent as the quality assurance.

SystemCo. The strategy expressed towards the customers and the cleaners was that the system would increase cleaners' sense of control regarding their work. The digitalization would make running and checking dispensers less of a problem, thus allowing for better planning and use of time. From a SystemCo point of view, the IoT system was a part in helping them transform their business strategy and make the move from product to service provision.

"[...] We have become a bit more than only a sanitations product provider. From being a provider, to becoming more like someone that's support... or help... you support [the customer] in a different way - you get a much closer relationship."

A major reason for moving in that direction was that there could only be so much innovation that could be done with the dispensers themselves analogously, and the products being sold would still have to be at a low price range to make sure that customers would not turn to any competitors. In order to maintain the customer base and attract new customers, the IoT solution was adopted and the dispensers were outfitted with general sensors that could fit within a multitude of dispensers, regardless of their shape.

\subsection{Technology-in-Use}

CleanCo. While the cleaners were all positive toward the system and stated that it did help them with their day-to-day tasks, one of the team leaders mentioned that they had one of the cleaners approach them and say that the system was leading to a significant increase in stress, and to some extent make them doubt in their ability to do their job. This aspect was to some extent dismissed and it was argued by the team leader that the cleaner in question did not have a "proper mindset" - meaning that the cleaners simply shouldn't let themselves get stressed out from the system, but instead embrace it as a tool, and seeing the "critical-time" more as a guideline than an actual requirement to instantly attend to. One of the team-leaders described it as;

"I've had one cleaner telling me that 'I'm bad since I take it too easy, leaving too many areas red, while [another cleaner] manages those cleaning areas off [not red]', and at the same time the cleaner is telling me that they are working too hard and don't know how long they can hold out before something, like, breaks - and that they need more help." 
Very little, if any, blame was given to the system itself, but rather it was somewhat shifted towards the cleaner, where the same team leader as above, was asked about the stress-aspect as a design flaw they stated that;

"There's a number of design flaws, however I wouldn't say that the stress aspect is a flaw in the system, instead it has... it's the human factor".

A similar aspect of "not having the proper mindset" was also expressed in a group meeting that featured both the SystemCo and CleanCo, where the SystemCo seemed to agree that if someone was being stressed by the system it was a question of that person's "mindset". The team leader said that cleaners would occasionally ignore some of the 'critical time', when sensors turned red, and continue working in their own pace - whereas the cleaner that was feeling stressed said that they would run to every area as soon as the sensors turned red.

Further it was also described by another team leader that it was important for them to make sure that the cleaners continuously used the system, as some of the cleaners had been doing their job for so long that they would clean from "muscle memory" rather than the indications from the system itself. The team leader argued that if the cleaners were not continuously exposed to the system, some of them would stop using it and revert back to their old habits and ways of working.

BuildingCo. One of the statistical views that the building/operations manager mentioned as their favorite ones was the 'total critical time', detailing the time within a user-defined time frame that the sensors showed as being 'red'.

As previously described, the IoT system was used by BuildingCo in order to make economic predictions, and as a baseline for price negotiations.

Regarding scheduling it was decided that the cleaners would still work the same hours with the system - mainly using the added time that was saved to be used within their frequency-based cleaning plan in order to maximize productivity. An initial fear that was noted by the building/operations manager was that;

\footnotetext{
"What we were afraid of was that there'd be some kind of 'Big brother is watching you' and those types of things, but it's not... [...] no one that I've heard from has said that there... was... problems, rather it was just cool that they got some new technical [things]."
}

From the managerial viewpoint there were no problems related to the surveillance aspect. Neither was it mentioned anything about the cleaner experiencing problems from the system, however it is possible that it had not been relayed to the building/operations manager from the team-leaders of the cleaners. However, overall, the building/operations manager expressed much positivity of the system itself and saw it as a useful tool.

SystemCo. During one of the interviews, two of the system providers described similar stories that many of the customers that had received the system were pleased with it, but that in some instances had been very weary of it initially such as;

"[...] We worked in a place where we got comments such as 'I've worked here for twenty years, don't come here and tell my how to clean, I don't want an... an app that tells me how to clean'", 
Respondent S01 also stressed the importance of getting both the cleaning personnel and the maintenance manager on board, in order to successfully market a system such as this - primarily because it could entail a large cost and that they needed employees in the organization ready to sell in the idea to the executive manager, stating that;

"What I've learned about the implementation is that you have to push this a lot - they have to be willing to change, and the operations managers have to... you don't just implement a system and hope that it solves itself, you have to work with the system".

Respondent S03 did note that there had been instances where they had attempted to market the system internationally, sometimes having unions evaluating their products before they could be installed. However, claims that some cleaners became stressed by the system were largely brushed off, and it was argued that the cleaner potentially was "thinking wrong" or simply did not have the correct "mindset".

Table 3 provides a summary of our findings grouped according to the three theoretical constructs and the views expressed by the three stakeholders. These findings are then discussed in the next section where we show how the stakeholders' technological frames influenced their perceptions of both opportunities and challenges with introducing IoT in the workplace.

Table 3. Summary of main findings

\begin{tabular}{|c|c|c|c|}
\hline \multirow{3}{*}{$\begin{array}{l}\text { Benefits } \\
\text { from } \\
\text { system }\end{array}$} & \multicolumn{3}{|l|}{ Theoretical construct } \\
\hline & Nature of technology & Technology strategy & Technology-in-use \\
\hline & $\begin{array}{l}\text { Stakeholder's } \\
\text { understanding of IoT, its } \\
\text { functionality, and its } \\
\text { possibilities }\end{array}$ & $\begin{array}{l}\text { Stakeholder's views on what IoT } \\
\text { might add to their organization } \\
\text { and what the reason is for } \\
\text { technology adoption }\end{array}$ & $\begin{array}{l}\text { Stakeholder's views on how IoT } \\
\text { will be used within the } \\
\text { organization, and what } \\
\text { consequences this will bring }\end{array}$ \\
\hline CleanCo & $\begin{array}{l}\text { - Viewed by a majority of } \\
\text { the team-leaders as a silver } \\
\text { bullet solution } \\
\text { - Most personnel believe it is } \\
\text { as an improvement over the } \\
\text { previous (analogue) method } \\
\text { of working }\end{array}$ & $\begin{array}{l}\text { - Useful tool in cleaning, less } \\
\text { useful for planning } \\
\text { - A way to statistically keep track } \\
\text { of work trying to make the } \\
\text { business more effective }\end{array}$ & $\begin{array}{l}\text { - Team-leaders state that some } \\
\text { cleaners are too stressed } \\
\text { because of the system } \\
\text { - If the cleaners aren't exposed } \\
\text { to the system or "forced" to use } \\
\text { it, its usage will diminish }\end{array}$ \\
\hline BuildingCo & $\begin{array}{l}\text { - Using the data generated } \\
\text { to create further value for } \\
\text { their own business } \\
\text { - Seen as a way to get an } \\
\text { overview of the cleaning } \\
\text { process }\end{array}$ & $\begin{array}{l}\text { - Using statistics as a means to } \\
\text { leverage better contracts with } \\
\text { both cleaners and system } \\
\text { provider } \\
\text { - Noticing discrepancies in the } \\
\text { performance of the cleaners } \\
\text { themselves }\end{array}$ & $\begin{array}{l}\text { - Being able to monitor } \\
\text { cleaning results in real time } \\
\text { and identify outliers } \\
\text { - Having cleaners work more } \\
\text { pro-actively instead of } \\
\text { reactively } \\
\text { - Changes in prizing from } \\
\text { system provider }\end{array}$ \\
\hline SystemCo & $\begin{array}{l}\text { - Helping businesses with } \\
\text { statistical analysis and } \\
\text { recommendations to } \\
\text { cleaning solutions } \\
\text { - Value creation for cleaners } \\
\text { through the addition of the } \\
\text { technology }\end{array}$ & $\begin{array}{l}\text { - Giving cleaners increased } \\
\text { control over their work and } \\
\text { duties } \\
\text { - Positioning themselves towards } \\
\text { a more service-oriented business } \\
\text { model } \\
\text { - Creating means for co-operation } \\
\text { with customers and cleaners }\end{array}$ & $\begin{array}{l}\text { - Important to get cleaners (and } \\
\text { possibly the union) to } \\
\text { embrace the system } \\
\text { - Having team-leaders of the } \\
\text { cleaners "sell" the system to } \\
\text { the management } \\
\text { - If workers feel stressed out, } \\
\text { they have to adjust their way of } \\
\text { thinking }\end{array}$ \\
\hline
\end{tabular}




\section{Discussion}

For CleanCo and BuildingCo, the implementation of the IoT system started out as what could be characterized as a digitization of operative maintenance work [29]. This was accomplished by moving the previously analogue schedules, cleaning-zone information and messaging in to the IoT system itself. The transmitted sensor data gave the cleaners the opportunity to directly interact with each area, receive real-time information about which action was required and then act upon the given information. This information, combined with data generated from the cleaners' average response time could then be accessed by the building/operations manager, providing them with a statistical overviews on $e . g$. how long it had taken a maintenance worker to clean a certain area, or what the average response time was from the moment that a sensor turned red to when it had been attended to (becoming green). This functionality brought on a form of digital convergence and a symbiotic relationship between technologies and organizational processes, described by [3,34] as pervasive, meaning that previously physical objects, such as the installed soap dispensers or paper towel dispensers in our case, are incorporated with digital technology.

The IoT system had further changed the way that the building maintenance was being done, where frequency-based maintenance (following a predetermined schedule) in some instances had been completely dropped in favor for a need-based maintenance; a reliance on the IoT system - while also generating less complaints regarding the cleaning when doing so. The cleaners continuous usage further rendered the digital technology to become what is described by [29] as 'infrastructural technology', where a, comparatively, analogue workplace moves in to the digital sphere and moves towards becoming a digital workplace, through the introduction of IoT driving digitalization.

One identified challenge with this type of IoT system is the aspect of monitoring, where this IoT system to some extent, arguably, was being used to monitor the process of cleaning, as described by the building manager - even if the cleaners did not express that they felt surveilled. While the user data became anonymized in the application; tying specific times to specific cleaners was something that could be done with relatively little effort, making the IoT system risk being used in a manner that previous research [16] labeled as 'active real-time intrusion' and 'highly intrusive'.

SystemCo stated that the opportunities provided by the IoT system functioned primarily to assist cleaners in their daily routines, so that they could work areas faster and with greater precision. However, it was also stated that the value created for SystemCo was the formation of new relationships with customers and the ability to strengthen the relationships with existing customers. This goes in line with previous research [20, 25], showcasing how connected and smart products allows for the formation of closer relationships between companies and their customer.

SystemCo further noted that a challenge in order to facilitate a successful implementation was that the team-leaders needed to be able to 'sell' the system to the management as a necessity, and also the willingness to work with the system from all participants by involving them and providing them with adequate resources in order to avoid problems, something previous research [4, 7] shows as being of importance. 
While the team-leaders for CleanCo had a shared vision about the system decreasing the time it took for the cleaners to attend to connected dispensers, it was evident that some of the cleaners themselves did not experience a simplification of their work, but rather the challenge of an increase in stress. This stress aspect that was not addressed to any major extent by either CleanCo or the SystemCo, and possibly not even known by the operations manager at BuildingCo. This points towards the same frame incongruence as described in the Theoretical Framework section [19] - where different individuals or groups of individuals do not share an understanding of what can be expected of the technology.

Should said frame incongruence persist or increase to the point where the cleaners' understanding and expectations proceed to differ significantly from BuildingCo, SystemCo or even the team-leaders, we argue that it has the potential to severely impact all of the aforementioned challenges and opportunities, as well as hampering a continued successful implementation of IoT within their workplace.

\section{Conclusions and Suggestions for Future Research}

In this study we set out to explore the question; What are the challenges and opportunities associated with introducing IoT in the workplace? Through our interviews with the stakeholders in the case of CleanCo, BuildingCo and SystemCo we have identified several opportunities as well as challenges present to each stakeholder.

One of the opportunities as described by BuildingCo was that the IoT system, allowed them much greater ability to monitor work, and receive detailed performance reports in regards to the cleaning - which could be used in negotiations and as baselines for future hires and identifying outliers in terms of cleaning output.

CleanCo experienced a faster workflow, and a way for the cleaners to work in a more pro-active manner; knowing which areas that needed attention. But the system was also a challenge for some of the cleaners, where they had described an increased level of stress and doubts in regards to their own performance - something that seemed largely brushed off by SystemCo and team-leaders, running the risk of problems arising further down the line.

The opportunity expressed by SystemCo was to form new connections with customers - and a much longer lasting relationship with the ones using the system. But in order to sell the system to new customers, and retain old ones, the challenge described was to get the cleaners on board with the IoT system, desiring to use it and to have them continue doing so throughout the implementation and use of the system.

In order to best meet these opportunities and challenges we argue that it is pivotal for each stakeholder to establish congruent views on what IoT can deliver, how value will be created, and for whom. Incongruent views among the stakeholders can, if not properly addressed, have a detrimental effect on both challenges and opportunities within the implementation and usage.

Through this study we have been able to showcase an empirical example of both challenges and opportunities related to the implementation of an IoT system in a workplace context. We argue that future research should delve deeper into the aspects 
of increased stress amongst users of similar systems and whether or not IoTimplementations in other successful or failed ventures was preluded by including all the actors to a similar extent in the value creation process.

\section{References}

1. Aral, S., Brynjolfsson, E., Van Alstyne, M.: Information, technology, and information worker productivity. Inf. Syst. Res. 23(3-part-2), 849-867 (2012)

2. Bresnahan, T., Brynjolfsson, E., Hitt, L.: Information technology, workplace organization, and the demand for skilled labor: firm-level evidence. Q. J. Econ. 117(1), 339-376 (2002). http://www.jstor.org/stable/2696490

3. Borgia, E.: The Internet of Things vision: key features, applications and open issues. Comput. Commun. 54, 1-31 (2014)

4. Botta-Genoulaz, V., Millet, P.A.: An investigation into the use of ERP systems in the service sector. Int. J. Prod. Econ. 99(1-2), 202-221 (2006)

5. Brynjolfsson, E., McAfee, A.: The Second Machine Age: Work, Progress, and Prosperity in a Time of Brilliant Technologies. WW Norton \& Company, New York City (2014)

6. Eloff, J.H.P., Eloff, M.M., Dlamini, M.T., Zielinski, M.P.: Internet of people, things and services - the convergence of security, trust and privacy. In: Proceedings from 3rd CompanionAble Workshop - IoPTS, Novotel Brussels - Brussels, 2 December 2009

7. Gallivan, M.J., Spitler, V.K., Koufaris, M.: Does information technology training really matter? A social information processing analysis of coworkers' influence on IT usage in the workplace. J. Manag. Inf. Syst. 22(1), 153-192 (2005)

8. Greengard, S.: The Internet of Things. MIT Press, Cambridge (2015)

9. Hsu, C.W.: Frame misalignment: interpreting the implementation of information systems security certification in an organization. Eur. J. Inf. Syst. 18(2), 140-150 (2009)

10. Klein, H., Myers, M.D.: A set of principles for conducting and evaluating interpretive field studies in information systems. MIS Q. 23(1), 67-93 (1999)

11. Kling, R., Jewett, T.: The social design of worklife with computers and networks: a natural systems perspective. In: Yovits, M.C. (ed.) Advances in Computers, pp. 239-293. Academic Press Inc., San Diego (1994)

12. Köffer, S.: Designing the digital workplace of the future-what scholars recommend to practitioners. In: Proceedings of the Thirty-Sixth International Conference on Information Systems, Fort Worth, USA (2015)

13. Kohli, R., Grover, V.: Business value of IT: an essay on expanding research directions to keep up with the times. J. Assoc. Inf. Syst. 9(1), 23 (2008)

14. Mason, J.: Qualitative Researching. Sage Publications, CA (2002)

15. Melville, N., Kraemer, K., Gurbaxani, V.: Information technology and organizational performance: an integrative model of IT business value. MIS Q. 28(2), 283-322 (2004)

16. Miller, C., Stuart Wells, F.: Balancing security and privacy in the digital workplace. J. Change Manag. 7(3-4), 315-328 (2007)

17. Monteiro, E., Rolland, K.H.: Trans-situated use of integrated information systems. Eur. J. Inf. Syst. 21(6), 608-620 (2012)

18. Orlikowski, W.J., Baroudi, J.J.: Studying information technology in organizations: research approaches and assumptions. Inf. Syst. Res. 2(1), 1-28 (1991)

19. Orlikowski, W.J., Gash, D.C.: Technological frames: making sense of information technology in organizations. ACM Trans. Inf. Syst. 12(2), 174-207 (1994) 
20. Porter, M.E., Heppelmann, J.E.: How smart, connected products are transforming competition. Harv. Bus. Rev. 92(11), 64-88 (2014)

21. Porter, M.E., Heppelmann, J.E.: How smart, connected products are transforming companies. Harv. Bus. Rev. 93(10), 96-114 (2015)

22. Ritchie, J., Lewis, J., Elam, R.G.: Selecting samples. In: Qualitative Research Practice: A Guide for Social Science Students and Researchers, p. 111 (2013)

23. Robey, D.: Computer information systems and organization structure. Commun. ACM 24 (10), 679-687 (1981)

24. Robey, D., Boudreau, M.C.: Accounting for the contradictory organizational consequences of information technology: theoretical directions and methodological implications. Inf. Syst. Res. 10(2), 167-185 (1999)

25. Saarikko, T., Westergren, U.H., Blomquist, T.: The inter-organizational dynamics of a platform ecosystem: exploring stakeholder boundaries. In: Proceedings from 49th Hawaii International Conference on System Sciences (HICSS), pp. 5167-5176. IEEE (2016)

26. Saarikko, T., Westergren, U.H., Blomquist, T.: The Internet of Things: are you ready for what's coming? Bus. Horiz. 60(5), 667-676 (2017)

27. Stankovic, J.A.: Research directions for the Internet of Things. IEEE Internet Things J. 1(1), 3-9 (2014)

28. Suchman, L.A.: Plans and Situated Actions: The Problem of Human-Machine Communication. Cambridge University Press, Cambridge (1987)

29. Tilson, D., Lyytinen, K., Sørensen, C.: Research commentary-digital infrastructures: the missing IS research agenda. Inf. Syst. Res. 21(4), 748-759 (2010)

30. Truex, D., Baskerville, R., Klein, H.: Growing systems in emergent organizations. Commun. ACM 42(8), 117-123 (1999)

31. Vermesan, O., Friess, P. (eds.): Internet of Things: Converging Technologies for Smart Environments and Integrated Ecosystems. River Publishers, Aalborg (2013)

32. Walsham, G.: Interpreting Information Systems in Organizations. Wiley, Chichester (1993)

33. Whitmore, A., Agarwal, A., Da Xu, L.: The Internet of Things-a survey of topics and trends. Inf. Syst. Front. 17(2), 261-274 (2015)

34. Yoo, Y., Boland Jr., R.J., Lyytinen, K., Majchrzak, A.: Organizing for innovation in the digitized world. Organ. Sci. 23(5), 1398-1408 (2012)

Open Access This chapter is licensed under the terms of the Creative Commons Attribution 4.0 International License (http://creativecommons.org/licenses/by/4.0/), which permits use, sharing, adaptation, distribution and reproduction in any medium or format, as long as you give appropriate credit to the original author(s) and the source, provide a link to the Creative Commons license and indicate if changes were made.

The images or other third party material in this chapter are included in the chapter's Creative Commons license, unless indicated otherwise in a credit line to the material. If material is not included in the chapter's Creative Commons license and your intended use is not permitted by statutory regulation or exceeds the permitted use, you will need to obtain permission directly from the copyright holder.

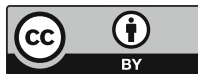

